Ana María Martínez de la Escalera

Facultad de Filosofía y Letras, UNAM

Friedrich Nietzsche: la promesa de una herencia

1. La muerte de un filósofo

El dolor verdadero de la vejez era la ausencia de examen, o sea, el horror de vivir sin ser observado.

Yalom $^{1}$

El veinticinco de agosto de 1900, en el mediodía de Weimar, Friedrich Nietzsche moría víctima de una dolencia que los médicos no acertarían a nombrar. Irónicamente, el cuerpo enfermo del que fuera el más agudo diagnosticador de nuestro presente, se resistía a ser diagnosticado. Entre tanto, la ciudad que albergara su agonía, no daba señal de duelo: muy pocos ciudadanos se enteraron del hecho, y de ellos sólo unos cuantos tuvieron la osadía de llorar al primer filósofo del porvenir. La muerte fue con seguridad una liberación del dolor y la letargia de la mente en los que estaba sumido, y sin duda, "del horror de vivir sin ser observado".

Ese día, mientras moría el hombre, el filósofo póstumo nacía a la historia, a la leyenda y a la memoria, las que, como es sabido, son imposibles sin la muerte. De ellas, es la memoria la encargada del duelo, de resu(s)citar al muerto (devolviéndolo a la

${ }^{1}$ Irving Yalom, 1999: 75. 
vida y renovando la incitación a pensar), mediante la narración. Pero, ¿de cuál vida hablamos? ¿Acaso nos referimos a la vida del hombre o a la del filósofo? ¿Existe, pues, diferencia entre ellas? ¿Sobrevive el filósofo a su cuerpo temiendo no saber morirse de muerte natural?

El filósofo transgrede la ley natural de la mortalidad, detiene la muerte porque escribe: en la escritura sobrevive a su propio corazón y vive una vida después de la vida ${ }^{2}$ que, desde los antiguos romanos, denominamos fama (o gloria, notoriedad, renombre, lustre y que, últimamente, se ha visto suplantada por esa parienta pobre que llamamos éxito público).

Se ha dicho que la fama es una dama muy difícil de complacer, y que Nietzsche nunca dio la impresión de haber conseguido dominar el sutil arte que requiere su cortejo. Es posible que su conocido talante melancólico lo hubiera inmunizado contra las lisonjas y zalamerías de la dama en cuestión y contra esa enfermedad de la vanidad que hoy llamamos narcisismo. Vacunado contra el entusiasmo pasajero que proporciona el éxito, confiesa a sus íntimos echar de menos el reconocimiento que a otros pensadores alemanes se les da por descontado. ${ }^{3}$ En sus

2 Para Nietzsche, el fílósofo siempre "nace póstumo" en relación a su tiempo. El nacimiento antes de tiempo es ciertamente una enfermedad que él habrá de soportar como una carga más entre sus otras dolencias físicas. Yalom conjura con acierto una imagen del filósofo de Sils Maria confesando: "Tengo períodos negros. ¿Quién no? Pero no me dominan. No forman parte de mi enfermedad, sino de mi ser. Podría decirse que tengo la valentía de padecerlos. Mi enfermedad pertenece al dominio del cuerpo, pero no soy yo. Yo soy mi enfermedad y mi cuerpo, pero ellos no son yo." Aunque el hombre y el filósofo habitan un mismo espacio, comen con la misma boca y sueñan los mismos sueños, la segunda de estas personas es quien domina la mayoría del tiempo. Como el rey que vive después que el rey ha muerto, el filosofo debe cargar, en su nombre, con la responsabilidad de haber vivido y haber hablado.

${ }^{3}$ Nietzsche sabía lo difícil que podía resultar a sus contemporáneos una escritura que transvaloraba lo más ínfimo, lo más despreciable en oro, "su oro" como él le llama en carta a Georg Brandes en 1888. Nietzsche, Epistolario, edición de Jacobo Muñoz, Madrid, Biblioteca Nueva, 1999: 226. Esta dificultad está destinada a la nobleza del espíritu o del ingenio, primero del filósofo, luego de su público; en carta a Peter Gast sostiene con orgullo inmitigable: "Noble es el eludir pequeños 
últimos años de vida lúcida, esa ausencia de reconocimiento profesional, sumada a un orgullo rebelde, le harán abrazar la condición de extranjero, en nada ajena a la condición de filósofo. La filosofía le ha enseñado que sólo el trabajo en la más completa soledad — soledad de la crítica - es provechoso, su propia naturaleza humana le recuerda lo contrario: no le será posible, según se disculpa en sus cartas, permanecer mucho tiempo extraño a la compañía de los otros. ${ }^{4}$

Es propio de ciertos filósofos defender la extranjería, la soledad y la completa alteridad del "espíritu libre" (aunque este último sólo sea -como sabemos- una ilusión) como el mejor remedio contra la estupidez del sentido común y el filisteísmo del pensamiento. Pero, no nos debemos dejar engañar por este "gran desasimiento" (HDH:37): el filósofo aspira a ser leído, aunque no necesariamente comprendido, ${ }^{6} \mathrm{y}$, sobre todo, desea

honores y la desconfianza contra el que alaba fácilmente. Noble es la duda en la comunicabilidad del corazón..." (J.M. Valverde: 155)

4 “...quien adivina algo de las consecuencias que implica todo recelo profundo, algo de los escalofríos y angustias del aislamiento a los que condena toda incondicional diferencia de enfoque a quien la sostiene, comprenderá también cuántas veces, para aliviarme de mí mismo, dijérase para olvidarme de mí mismo por un tiempo, he intentado resguardarme en cualquier parte, en cualquier veneración, enemistad, cientificidad, liviandad o estulticia; también por qué, cuando no he encontrado lo que necesitaba, he tenido que procurármelo artificiosamente, falseando o inventando". (HDH, Prefacio: 35 ) "Pero lo que una y otra vez necesitaba más perentoriamente para mi curación y mi restablecimiento era la creencia de que no era el único en ser de este modo, en ver de este modo, una mágica sospecha de afinidad e igualdad de puntos de vista y de deseos, un descansar en la confianza de la amistad, una ceguera a dúo sin recelo ni interrogantes, un goce en los primeros planos, superficies, lo cercano, vecino, en todo lo que tiene color, piel y apariencia." (HDH: 36)

5 “...el gran desasimiento se opera súbitamente, como un terremoto: el alma joven de repente sacudida, desprendida, arrancada, ella misma no entiende lo que sucede. Un impulso y embate la domina y se apodera de ella imperiosamente; se despiertan una voluntad y un ansia de irse, a cualquier parte, a toda costa; flamea y azoga en todos sus sentidos una vehemente y peligrosa curiosidad por un mundo ignoto". (HDH: 36)

${ }^{6}$ Respecto a Humano, demasiado humano escribe con una marcada ironía: “...es precisamente en Alemania donde ha sido leído más negligentemente, donde peor ha sido oído. ¿A qué se debe esto? "Exige demasiado", se me ha respondido, 
influir en la vida del pensamiento y en las acciones de los hombres; anhela dejar una huella, su huella. En realidad, está convencido de que ese es su destino. ${ }^{7}$ Por lo visto, la melancolía del filósofo ${ }^{8}$ que sobreviene con la conciencia de su propia mortalidad, produce un deseo incolmable de sobrevida (deseo de obra le llama acertadamente Valverde; Nietzsche le llamará "voluntad de salud"), es decir de alegría del pensamiento, de gozosa potencia capaz de derrotar a la muerte. Por su parte, la civilización occidental no ha abandonado a su suerte a los poetas y a los filósofos; ha inventado instituciones como la gloria, la fama y la notoriedad para dar la batalla final contra la

"se dirige a hombres sin el apremio de groseros deberes, requiere sentidos delicados y refinados, precisa abundancia de tiempo, de claridad de cielo y de corazón, de otium en el sentido más audaz: sin excepción, buenas cosas que nosotros alemanes de hoy no tenemos y por tanto tampoco podemos dar". Tras una respuesta tan amable, mi filosofía me aconseja callar y no hacer más preguntas; máxime si, como dice el proverbio, en ciertos casos uno sólo sigue siendo filosofo si calla." (HDH: 40-41)

7 "Nunca he percibido con mayor claridad la gran influencia de mis ideas", escribe a Peter Gast en 1888." La novedad, el valor de innovar, es en ellas realmente enorme. Por lo que respecta a las consecuencias que puedan traer le diré que miro mis manos con cierta desconfianza, pues me parece tener "entre ellas" el destino de la Humanidad." (Epistolario: 240) A continuación, sin embargo, profiere reparos: "No quisiera presentarme ante los hombres como profeta 0 monstruo moral."' Y pronostica: "Le juro a usted que dentro de dos años tendremos a toda la tierra en convulsiones. Soy una fatalidad." Epistolario: 240. Aun antes, a Deussen, le había confiado que por penosa que pareciera su labor, se le aparecia tan decisiva que si llegaba a ser comprendida "dividirá la historia de la Humanidad en dos mitades: “...Ser cristiano será, en adelante, indecoroso." (E.: 236) Quizás exceso de orgullo por su parte, pero también deja claro, pese a ciertos lectores contemporáneos (Rorty en particular), que Nietzsche rescataba la mision de filosofo sobre cualquier otra consideración. Tarea penosa pero decisiva, a condición de corroborar la "alegría del género". (Epistolario: 237)

${ }^{8}$ Esta melancolía es, y no es, una enfermedad mental: sobre todo es una marca ontológica. La fórmula latina post festum nos ayudará a entender la idea que acompaña siempre al melancólico: la idea de un pasado irrevocable con el cual cuesta trabajo relacionarse. El melancólico vive la relación con su yo como si se tratara de "yo ya sido" en lugar de como un "eso aún no es". Nietzsche ha sugerido en La Gaya Ciencia que debemos superar el resentimiento; alzarse victorioso contra el resentimiento significa la posibilidad de querer lo que ha sido, de sostener "así he querido que fuera" del amor fati. Sin embargo en Nietzsche jamás veremos resolverse la oposición entre el "yo ya sido, yo rebasado" aceptado y asumido y el porvenir, el "eso que está por venir". 
muerte: ellas constituyen a su manera, modalidades de la memoria y el olvido.

La fama

La recompensa final otorgada a los muertos es no tener que volver a vivir ya más.

Yalom $^{9}$

Caprichosa como toda mujer a la que parodia, la gloria es, no obstante, una institución viril. Aliada del poder y la barbarie, la fama se ha relacionado más con sus detentadores, que con sus víctimas. El lustre del nombre o notoriedad precisa naturalezas fuertes, arrolladoras, poco propensas a la compasión y la piedad. La tradición occidental cristiana reconoce pocas heroínas, poetas o filósofas, aunque preserva el recuerdo de un número elevado de santas y mártires. Pero la santidad es algo muy distinto de la gloria, la fama y el lustre. Mientras la primera condición acepta rendidamente la muerte propia en nombre del otro, las tres siguientes hacen como si la muerte y el otro -como si la muerte del otro - no existieran. Desde luego, para la gloria no es el hombre el que pervive, sino el nombre propio y por ende ha decidido sólo ser reconocida mediante la voz "re-nombre". En nuestra cultura la fama, la vida después de la vida del filósofo, no alcanza a distinguirse del nombre propio. Platón y el platonismo o Aristóteles y el aristotelismo son nombres que damos indistintamente a un individuo, su obra, su herencia y su influencia sobre generaciones futuras. El exceso de significación, de historia que el nombre indica, es lo que denominamos renombre. A estos efectos, el renombre actúa como una tendencia a la repetición, a la transmisión y conservación de lo dicho;

${ }^{9}$ Irving Yalom, ibid.: 94. 

unidos y centrados los conceptos y categorías que constituyen el campo semántico de una filosofía, que mantiene el equilibrio entre el estilo autoral (las maneras del decir) y la dimensión realizativa del discurso singular (las maneras del hacer). La fama es la encargada de inmovilizar la semántica y la pragmática de cada autor en cuestión, actuando no a favor del tiempo sino a contrapelo: negándose a resignificar y contextualizar los textos, eliminando el poder de los lectores sobre la escritura y la ocasión, oportunidad y posición que marcan toda lectura.

La gloria es una hija malagradecida de la institución retórica que, tras haberla criado con largueza, se ha dado cuenta que ha llegado el momento de meterla en cintura. ${ }^{10}$ Ningún producto

${ }^{10}$ Es posible argumentar que la fama, o su concepto, pertenece de hecho a la nomenclatura de la disciplina retórica y por tanto es regulada por sus principios (oportunidad y posición). En este sentido la retórica le ha prestado el auxilio de una forma propia, el paradigma o exemplum; le ha puesto a su disposición una operación, la alegoresis, confiriéndole con todo ello, una peculiar relación con la verdad y la historia. La fama no le es extraña a Occidente: durante largos períodos el orgullo del poeta sería una marca de su valía y un símbolo de su fama. Desde los maestros de verdad de la Antigüedad (M. Detienne, Los maestros de verdad en la Grecia arcaica, Barcelona, Taurus, 1974), pasando por el rétor y el sofista, hasta la figura del maestro de retórica de nuestra era cristiana, que enseña sabiduría fuera de los confines de la institución de enseñanza, la fama depositada en el nombre propio será un útil, una mercancía tanto como una virtud sagrada. Sin embargo, para el siglo I de nuestra era, las cosas habían cambiado. El padre de Séneca, por ejemplo, nos da un indicio claro de cómo la clase culturalmente privilegiada de la Roma imperial había empezado a desconfiar de una fama sin el respaldo institucional, es decir político: así se sospechaba de la filosofía de las sectas, esa sabiduría que era también forma de vida le resultaba odiosa a quien la fama ya no era un requisito, sino un impedimento. La política exigía al hombre público una cierta actualidad que la noción de fama despreciaba por oportunista. A partir de ese siglo aparece una nueva forma de exemplum: el personaje ejemplar (eikon, imago) que designará, entonces, la encarnación de una virtud en una figura humana, no en un nombre. Es la alegoría que después será refuncionalizada a lo largo de diez siglos: del $v$ al xv en Europa. Se establece un repertorio de imágenes para su empleo en la escuela y los textos o manuales escolares. En Dante hay numerosos ejemplos que han sido tratados con amplitud. El ejemplo es separable y tiene la capacidad de autonomizarse de su contexto y subsistir y pervivir por muchos siglos después de su primera invención. Hoy en día, por sólo citar un caso, el actual Papa ha hecho un uso muy completo de su historia personal en Polonia, durante la Segunda Guerra europea. Pero, no nos adelantemos: es conocida la anécdota que refiere 
del ingenio humano puede librarse del uso, del paso del tiempo y del olvido, del azar de las circunstancias. La fama ha querido negar la historia, el cambio; no ha podido sin embargo imponer relaciones estables, más allá del uso y el abuso, entre los lectores y las obras. Como renombre, la fama es una forma de acción del tiempo sobre el nombre propio, que lo duplica, lo convierte en su propia imagen o emblema paródico. ${ }^{11}$ Pero, con el fin de conservar y transmitir esa misma imagen, debe olvidar convenientemente lo que considera innecesario, lo irrepetible y original que habita la obra.

Es ahí donde finalmente se justifica - paradójicamente-el orgullo alegre del filósofo: la fama que se desteje por la noche, debe tejerse por la mañana. Porque Nietzsche sabe que no ha sido comprendido, y que quien quiera comprenderlo deber iniciar, siempre una vez más, el lento aprendizaje de la lectura. De hecho somos conscientes de la dificultad de leer e interpretar a

como Enrique de Avranches, dirigiéndose a Federico II, a cuyo servicio ha decidido ponerse, le habría de recordar que él era "el mejor poeta de nuestro tiempo" (versos 19-21), agregando que "en la esfera del intelecto reina Dios, en la de las cosas tú, en la de la palabra yo (versos 53-66). Por si ello no hubiera calado hondo en la mente soberana, concluye que "en mi dominio yo también soy rey (66-69). ¿Demuestra el poeta poco tacto, según Curtius nos diera a entender, o se trata de una formula habitual? ¿Había su cultura aprendido a tolerar y a esperar esta conducta megalómana de sus poetas? Con seguridad así ha sido; sin embargo, para el siglo XIX las cosas habrian de cambiar. La postura extravagante, notoriamente diferente del sabio sólo mueve a risa, o peor aún, a una mueca condescendiente. ¿ $\mathrm{Ha}$ blará ello del carácter del poeta y del sabio, o más bien de la nueva moralidad (protestante) de nuestra cultura? Mucho tiempo antes, en el Roman de la Rose, Jean de Meung hace un elogio de la poesía a la vez que se queja con amargura de una época que no sabía ya reconocer la valía del sabio. La alabanza de la literatura y del papel del clérigo o el filosofo es directa en los versos 18,604 en adelante; el lamento es igualmente claro: los que se dedican a cosas del espíritu no deberían sufrir necesidad. Esto no incluía al filósofo escolástico, al universitario protegido por su institución oficial.

${ }^{11}$ El emblema, o más bien la alegoría, posee la paradójica propiedad de nombrar al otro, y a la vez de decir algo diferente de lo que ofrece a la lectura, algo que el hombre nunca podrá aspirar a ser: lo intemporal. Esta situación imposible es la que impide que la imagen logre el objetivo de sustituir totalmente al ser humano; la memoria entonces fallará una y otra vez al recordarlo, y el emblema se volverá su propia parodia. 
Nietzsche el día de hoy, incluso sin el agregado de la falsificación de su pensamiento (como sugiriera Colli), argumento que está siendo revisado a últimas fechas.

\section{La filología}

El segundo prólogo a su libro Aurora, firmado en la Alta Engadina en 1886, insiste en esta modalidad de lectura, más propia de un filólogo que de un filósofo. Con el tiempo invertirá su fórmula declarando que hace falta un filósofo para evitar la tiranía del lenguaje sobre el pensamiento. Oigamos al mismo Nietzsche:

"Pero, en fin de cuentas, ¿por qué habremos de decir tan alto y con tal ardimiento lo que somos, lo que queremos y lo que no queremos? Miremos el asunto más friamente, más cuerdamente,..." Y agrega: "Ante todo, digámoslo lentamente...Tal libro y tal problema no tienen prisa; $y$, además, nosotros somos amigos del "lento" yo, así como mi libro. No en vano he sido filologo, y aún lo soy. Filólogo quiere decir maestro en la lengua lenta, y que acaba por escribir lentamente. Pero no sé que sea esto sólo un hábito en mí, es que es un gusto mío, ¿un gusto maligno quizás? No escribir acerca de otra cosa que de aquello que podría desesperar a los hombres que "se apresuran". Pues la filología es ese arte venerable que ante todo exige una cosa de sus admiradores: mantenerse aparte, tomarse tiempo, hacerse silencioso, hacerse lento; un arte de orfebrería y una pericia de orfebrería en el conocimiento de la "palabra", un arte que exige un trabajo sutil y delicado y que no realiza nada si no trabaja con lentitud. Pero precisamente a causa de ello es hoy más necesario que nunca, justamente por la circunstancia de que encanta y seduce más, en medio de una edad de "trabajo", es decir, de precipitación, de apresuramiento indecente que se enardece y que quiere acabar pronto todo lo que emprende, incluso el libro. Este arte a que me refiero...enseña a leer bien, es 
decir a leer despacio, con profundidad, con reparos y precauciones, con dedos y ojos delicados... Amigos pacientes, este libro no pide más que lectores y filólogos perfectos; "aprended" a leerme bien". (Aurora: 16)

¿Quién entre nosotrós le ha tomado la palabra? ¿Quién se ha atrevido a aceptar el convite de sus palabras y ha entrado a la "fiesta del pensamiento"? Nos hemos quedado aguardando a la puerta temerosos, quizás, de que la fiesta de la lengua fuera, en el fondo, la celebración del orgullo desmedido. Es conveniente recordar que detrás de la vanidad del filósofo hay un legado que es preciso recuperar, actualizar.

\section{Su legado}

Los maestros deben ser despiadados porque el mundo es despiadado, vivir y morir son despiadados...

Yalom $^{12}$

Nietzsche no parece haber tenido dudas respecto al papel que su obra debía jugar en la historia de Europa. Así lo hace saber a Helen Zimmern, quien evoca un encuentro con el filósofo en 1884: "Una vez me confió que esperaba que un día se creara una cátedra dedicada enteramente a su filosofía." (Claudio Pozzoli, Nietzsche nei ricordi e nelle testimoniarze dei contemporanei, Milan Rizzoli, 1990: 333) Parecía pensarlo no tanto como un reconocimiento a su valía como pensador cuanto una nueva necesidad escolar para los tiempos que se avecinaban: una manera de educar con vistas al porvenir. Desafortunadamente su interés en la enseñanza y en su porvenir ${ }^{13}$ solo sería

12 Irving Yalom, ibid.: 90.

13 Friedrich Nietzsche, 1977. 
tomado en cuenta por la escuela fascista, la que puso en acto una sistemática de la voluntad de poder.

Además de habernos legado la posibilidad de concebir a la filosofía como fiesta del pensamiento — celebración de la destrucción de la metafísica-, Nietzsche nos ha prometido recuperar el vínculo entre vida y obra, entre la acción y el decir. No se trata sin embargo de una promesa fácil de consumar: exige ser "hombres venidos del extranjero" (solitarios) en la propia lengua, en la propia institución, en la historia. Vivimos "tiempos de oscuridad" (Arendt), tras la muerte de dios, la promesa ha dejado de ser esperanza de renacimiento, se ha vuelto una promesa sin medida común, sin garantía. Sin una promesa que pueda ser medida por su realización, sino por lo que ella misma pone en acción hoy, cuando se la enuncia con claridad, necesitamos ser cuidadosos. Quizás, como Heidegger pensaba, la promesa nietzscheana es el eterno retorno: el asumir el pasado sin reserva ni remordimiento y el porvenir sin utopía sentimental. En este sentido, no salvaremos a Nietzsche desconociendo lo que en su nombre fue pronunciado o lo que en su nombre fue puesto en acción, pero tampoco lo podemos exonerar de la responsabilidad filosófica e histórica moralizando su voluntad de poder o su nihilismo. Quizás sólo la genealogía de su obra pueda comprometerse con una responsabilidad más allá de lo jurídico, de lo directamente imputable. Debemos interrogar al pensamiento nietzscheano más que a la culpa. Así, la promesa de la escritura nietzscheana enunciada en la expresión "somos hombres que nacemos póstumos" ser una incitación al pensamiento antes que una renuncia. 


\section{Bibliografía}

Agamben, Giorgio, Lo que queda de Auschwitz, Valencia, Pre-Textos, 1999.

BARTHES, Roland, El susurro del lenguaje. Más allá de la palabra y la escritura, Barcelona, Paidós, 1984.

BatallLE, Georges, Sobre Nietzsche. Voluntad de suerte, $2^{\mathrm{a}}$ ed., Madrid, Taurus, 1979.

Deleuze, Gilles, Spinoza. Kant. Nietzsche, Barcelona, Editorial Labor, 1974.

Derrida, Jacques, Memorias para Paul de Man, Barcelona, Gedisa, 1989.

—, La filosofía como institución, Barcelona, Granica, 1984.

NieTzSChE, Friedrich, La voluntad de poderio, Madrid, EDAF, 1991.

- La volontà di potenza. Fragmentos póstumos ordenados por

Peter Gast y Elisabeth Förster-Nietzsche, nueva edición italiana a cargo de Maurizio Ferraris, Milán, Bompiani, 1992.

- Aurora, en Obras Completas II, $6^{\mathrm{a}}$ ed., Buenos Aires, Aguilar, 1967.

__ El porvenir de nuestras escuelas, Barcelona, Tusquets editor, 1977.

—, El libro del filósofo, Madrid, Taurus, 1974.

—, La Gaya Ciencia, Barcelona, Olañeta editor, 1984.

Yalom, Irving D., El día que Nietzsche lloró, Buenos Aires, Emecé, 1999.

V ALVERde, José María, Nietzsche, de filólogo a Anticristo, Barcelona, Planeta, 1993.

Vattimo, Gianni, Introducción a Nietzsche, Barcelona, Ediciones

- Península, 1987. 